\title{
De Apologética Trinitaria al Diálogo Interreligioso
}

\author{
Juan Carlos Múnera \\ FUNDACIÓN UNIVERSITARIA LUIS AMIGÓ (COLOMBIA) \\ juancocha@libero.it
}

\begin{abstract}
Resumen: En el presente artículo se plantea la concepción tradicional musulmana de la creencia cristiana en la Trinidad a través del comentario coránico Tafsìr al-Manār (1898-1935), de los autores Muhammad'Abduh y Muḥammad Rashīd Rị̣ā, figuras importantes del reformismo islámico moderno. El propósito no es renovar ni invitar a las discusiones teológicas entre el Islam y el Cristianismo, sino más bien presentar la especificidad y diferencia de la apologética de tiempos modernos (siglos XIX a inicios del $\mathrm{XX}$ ) en relación al pasado. Igualmente, se introduce al cambio de la apologética entre ambas religiones al diálogo interreligioso en la nuestra época contemporánea.
\end{abstract}

Palabras clave: Trinidad, unicidad divina, diálogo, exégesis, apologética.

Abstract: This article presents the traditional Muslim conception of the Christian belief in the Trinity through the Qur'anic commentary Tafsir al-Manār (1898-1935), of the authors Muhammad'Abduh Muhammad Rashīd Rị̂ā, important figures of the Modern Islamic reform movement. The purpose of this work is not to renew or to invite to theological discussions between Islamand Christianity, but rather to present the specificity and difference of apologetics of Modern times (XIX to first part of XX) compared to the past. Similarly, the change from this kind of apologetics to interreligious dialogue in the Contemporary world is introduced as well.

Keywords: Trinity, divine unity, dialogue, exegesis, apologetics.

\section{INTRODUCCIÓN}

El objetivo de este trabajo no es el de reiniciar polémicas entre las dos grandes religiones monoteístas actuales: Islam y Cristianismo. Por el contrario, el propósito principal es mostrar nuevos caminos del diálogo interreligioso tanto en el plano teológico, como de vida y cooperación 
entre adeptos a diferentes tradiciones religiosas. En este sentido y para iniciar este recorrido, se partirá de la presentación de la concepción islámica tradicional de la creencia en la Trinidad a través del comentario o explicación del Corán: Tafsìr al-Manār ${ }^{1}$, reconocido como uno de los trabajos exegéticos principales e influyentes de la época Moderna. Esta exégesis manifiesta la postura clásica del Islam en relación a la creencia en la Trinidad y en otros aspectos relacionados con la visión islámica del cristianismo. Sin embargo, el comentario y sus autores, especialmente Rashīd Rị̣ā, muestran una nueva tendencia iniciada en tiempos modernos en la forma de conducir los planteamientos apologéticos entre las dos religiones.

Tafsìr al-Manār es un trabajo de exégesis ${ }^{2}$ incompleto $^{3}$, consta de doce volúmenes, iniciando con la disquisición sobre la primera süra o capítulo del Corán al-Fätih a: La Apertura y finalizando con la süra doce Yusuf: José, versículo 52 en el volumen número doce (12). Sus autores, el egipcio Muhammad 'Abduh (1849-1905) ${ }^{4}$ se reconoce como autoridad principal, y respetado como unos de los iniciadores del reformismo islámico moderno5 . El libanés Muhammad Rashīd Rị̣ā (1865-1935)6, su editor y segundo escritor; en realidad la idea de iniciar el comentario fue de este último y expuesta a su maestro Muhamamd 'Abduh; así se integraron parte de las enseñanzas que 'Abduh impartía en la universi-

M. R. Rip̣ā, Tafsīr al-Qur'ān al-Karìm al-Musammā Tafsīr al-Manār, Ăğzā' 1-12 (Dār al-Manār, al-Qāhira, 1954); en este artículo será citado como TM 1: 1, el primer número indica el volumen y el segundo las páginas.

2 Todo comentario del Corán parte de un análisis lingüístico, aborda términos, su origen y significados, se complementa con explicaciones precedentes de otras autoridades y un análisis teológico y legal de cada versículo.

3 El Corán contiene 114 süras o capítulos, Tafsìr al-Manār solo aborda los primero 12 de ellos.

4 Muhammad 'Abduh, teólogo, jurista, erudito y reformador egipcio. Este fue profesor de la Universidad de al-Azhar, la más importante de Egipto y el mundo islámico. 'Abduh ocupó el puesto de $M u f t i$, la principal posición religiosa del país, reconocido por ser uno de los principales representantes del reformismo islámico moderno.

5 J. O. Voll, "Renewal and Reform in Islamic History: Tajdīd and I lāh" en Voices of Resurgent Islam, J. L. Esposito (dir.) 32-48, (Oxford University Press, New York and Oxford, 1983) 32-48.

6 Rashīd Riḍā fue un teólogo, intelectual y comunicador libanés. Este hizo parte del movimiento reformista islámico pero con ideas más conservadoras que su maestro Muhammad 'Abduh. 
dad de al-Azhar ${ }^{7}$ del Cairo. El tafsīr contiene los aportes de Muhammad 'Abduh y los complementos que integra Rashīd Riḍā. En este trabajo exegético se indican las contribuciones de Muhammad 'Abduh por: qāla al-udtād al-Imām: el profesor e imamdijo. Y para las contribuciones de Rashīd Rị̣ā indica: aqūlu: yo digo o afirmo. Sin embargo, Muhammad 'Abduh murió en 1905 y Rashīd Rị̣a continuó con la labor hasta su muerte en 1935. Las primeras explicaciones sobre el Corán fueron publicados en la revista al-Manār: El Faro ${ }^{8}$, la cual fue creada en Cairo por Rashīd Riḍā para promover las ideas y valores del movimiento de reforma del Islam desde 1898 hasta su muerte en 1935.

El reconocimiento y valoración de Tafsīr al-Manār se basa principalmente por varios elementos importantes, entre ellos: la postura de Muhammad 'Abduh hacia la Modernidad. Entre las características principales que se destacan del pensamiento de 'Abduh, se puede afirmar que el manifestó un diálogo con las ciencias modernas, una apertura hacia el Occidente, aunque sin descartar la posibilidad de crítica y admiración hacia este, como se ha llamado comúnmente una especie de amor y odio hacia el Occidente; y por otra parte una actitud apologética vis-avis el cristianismo y el Occidente; otras característica suya fue la utilización y valoración de la razón aun para explicar las cuestiones religiosas; también manifestó un deseo de reforma del Islam en su forma de interpretar la tradición en relación a los desafíos de los tiempos modernos y la aplicación de la ley a los diferentes contextos históricos y sociales; se debe tener en cuenta además los niveles de significado de su revelación, sin desprenderse ni renegar del legado religioso y cultural del Islam.

Tafsìr al-Manār hace parte de la tradición exegética islámica mejor denominada como la ciencia del tafsìr, la cual es la base para la aplicación e implementación de los designios del Corán, la sunna del profeta del Islam y la ley Islámica. La palabra tafsìr significa literalmente descubrir, levantar el velo, indica la acción de la luz al alba, del amanecer que ilumina la oscuridad de la noche. Por consiguiente, tafsìr viene a ser explicado como la iluminación o clarificación de los significados diver-

$7 \quad$ La Universidad de al-Azhar es la más antigua del mundo Islámico, fue fundada en 975 durante la dinastía Fatimida en Egipto (909-1171). Esta es considera hasta hoy como las más importante y prestigiosa del Islam sunita.

8 M. R. Rip̣ā, Mağallaal-Manār, al-Muğalladāt 1-35 (Dār al-Manār, al-Qāhira, 1315-1354 H/1897-1935 CE). 
sos de los versos del Corán. Por esto, tafsìr es la ciencia de la interpretación, de explicar de hacer exégesis coránica". Tafsīr ha sido reconocido como la interpretación ortodoxa, basada en una cadena de transmisores reconocidos y aceptados. Por el contrario, táwīl es otra forma de interpretación pero con connotación alegórica y esotérica. Esta forma de interpretación no está basada en la tradición oficial o en lo que se considera ortodoxo en la historia de la exégesis coránica ${ }^{10}$ y puede apoyarse en opinión personal, el uso de la razón e investigación personal. Lo cual puede dar motivos de duda ${ }^{11}$.

El comentario coránico en Tafsìr al-Manār manifiesta una tendencia apologética como se afirmó anteriormente. La tradición apologética entre el cristianismo y el Islam se basó principalmente antes de la Modernidad en la presentación de doctrinas de la religión del otro (cristiano o musulmán) para ser rechazadas de acuerdo a la propia creencia. $\mathrm{O}$ aún a base de diálogos entre dos adeptos, uno de cada religión ${ }^{12}$. La tendencia apologética de la Modernidad se presentó tanto de la parte de los occidentales (cristianos protestantes o católicos europeos y norteamericanos) y de los musulmanes en el Medio Oriente y Asia Central o del subcontinente indiano. Lo nuevo de la apologética especialmente en el siglo XIX y continuado en la primera parte del siglo XX, consistió en presentar la refutación de la religión del otro, basándose en textos principales y fuentes primarias de la tradición, ya sea del Islam como del cristianismo. Por otra parte, los participantes manifestaron domino de las lenguas del otro: árabe, urdu, griego, hebreo o también francés e inglés. Todo esto

9 M. Ayoub, The Qur'an and Its Interpreters, Volume 1 (State University of New York Press, Albany, NY, 1984).

18-19; C. Gilliot, "Exegesis of the Qur'ān: Classical and Medieval" en EQ: Encyclopaedia of the Qur'an, Volume 2: E-I, J. M. Mc Auliffe (dir.), (Brill, Leiden, 2002) 99-124.

10 La exégesis coránica o tafsīr, hace parte de las ciencias islámicas, especialmente en las dedicadas a la hermenéutica. Guilliot, "Exegesis of the Qur'ān: Classical and Medieval", 99.

11 A. Rippin, "Tafsīr" in Encyclopedia of Religion, Second Edition, Volume 13, L. JonEs (dir.), (Macmillian Reference USA -Thomson \& Gale, Farmington, Hills (MI), 2005) 8950.

12 Ver: J. M. Gaudel, Encounters \& Clashes: Islam and Christianity in History, Vollume I: A Survey and Volume II: Texts, "Collection Studiarabo-islamicidel PISAI" No 15 (PISAI, Roma, 2000). 
fue motivado por el colonialismo europeo, la imprenta y el desarrollo de la prensa escrita y el desplazamiento humano en estas regiones.

\section{REFERENCIAS DEL CORÁN SOBRE LA TRINIDAD}

En el Corán, la escritura sagrada del Islam, se encuentran varias referencias al concepto de la trinidad cristiana. El término árabe tā $\overline{l u} \underline{t}$ : trinitad no aparece como tal sino el término țaläta: tres. Hay tres referencias explícitas, cada una de ellas trata de negar esta creencia sobre la naturaleza de la divinidad, Dios un ser único en tres personas. Una primera referencia en el Corán es:

¡Gente de la Escritura! ¡No exageréis en vuestra religión! ¡No digáis de Alá sino la verdad: que el Ungido, Jesús, hijo de María, es solamente el enviado de Alá y Su Palabra, que Él ha comunicado a María, y un espíritu que procede de Él! ¡Creed, pues, en Alá y en Sus enviados! ¡No digáis ‘Tres'! ¡Basta ya, será mejor para vosotros! Alá es solo un Dios Uno. ¡Gloria a Él! Tener un hijo... Suyo es lo que está en los cielos y en la tierra... ¡Alá basta como protector! (Corán 4: 171).

Este texto especifica que Jesús es un enviado (uno de los profetas), hijo de María la cual es reverenciada por ser ejemplo de creyente y a quien se le dedica la süra o capítulo 19 y que lleva por título: Maryam. Por otra parte el en versículo se rechaza el Espíritu como procedente del Mesías, más bien se realza la doctrina establecida sobre el espíritu de Dios concedido a los profetas y muchas veces identificado con el ángel Gabriel en el Corán (Q. 19: 16-21); algunos otros versículos se refieren a Jesús y al espíritu de Dios concedido a Este (Q. 2: 87; Q. 2: 253; Q. 5: 110; Q. 16: 102).

Una segunda referencia declara: "No creen, en realidad, quienes dicen: 'Alá es el tercero de tres'. No hay ningún otro dios que Dios Uno y, si no paran de decir eso, un castigo doloroso alcanzará a quienes de ellos no crean"” (Corán 5: 73). El versículo asevera la unicidad divina, y cataloga de infieles a quienes profesan tal creencia en Dios como el țālit tercero de taläta: tres, además de asegurar un castigo merecido a tales creyentes. Y la tercera referencia directa es la siguiente:

Y cuando dijo Alá: “jJesús, hijo de María! ¡Eres tú quien ha dicho a los hombres: ‘¡Tomadnos a mí y a mi madre como a dioses, además de tomar a Alá'?”. Dijo: “¡Gloria a Ti! ¿¿Cómo voy a decir algo que no tengo por verdad? Si lo hubiera dicho, Tú lo habrías sabido. Tú 
sabes lo que hay en mí, pero yo no sé lo que hay en Ti. Tú eres Quien conoce a fondo las cosas ocultas. (Corán 5: 116).

El versículo alude a una creencia existente o tal vez a un concepto erróneo al incluir a María como una de las tres personas de la Trinidad. Esta puede ser una referencia a la secta o grupo religioso de los Coliridianos. Epifanius of Salamis del siglo 4 d.C. ${ }^{13}$, los describe como una secta, formada por mujeres principalmente y ubicados en Arabia, quienes tomaban a María como una diosa ${ }^{14}$. Su nombre viene del griego collyris que significa pan o torta, y recuerda la práctica de mujeres que ofrecían panes a la diosa Astarté en Fenicia ${ }^{15}$. El verso también coloca al Mesías quien se desvincula de la asociación divina y refuerza la omnisciencia divina.

Otros versículos como Corán 19: 88-93, Corán 23: 91 y Corán 112: 1-4 aluden a la Trinidad y se oponen totalmente a tres temas cruciales: la adopción, la asociación o cualquier iniciativa de engendrar un hijo divino. Además reiteran la unicidad divina, la omnipotencia de Dios; Dios es incomparable como también niegan cualquier jerarquía de dioses y acciones en la creación. Hay un gran número de versículos que mencionan a Jesús como Isa, el profeta, entre tantos como los demás del antiguo testamento. $\mathrm{O}$ también como el Mesías, los cuales reiteran su rol como profeta, la negación de su divinidad o asociación con Dios. Estos no serán tratados en este artículo aunque algunos sí son mencionados por Rashīd Riḍā y los utiliza en los pasajes del comentario escogidos para esta presentación.

\section{DISCUSIÓN APOLOGÉTICA ENTRE MUSULMANES Y CRISTIANOS EN EL SIGLO XIX}

A mediados del siglo XIX, se originó una discusión en el subcontinente indio entre orientalistas y musulmanes, llamada la controversia

13 Epifanio de Salamis (c.310 0 320-403) fue un obispo, considerado uno de los padres de la iglesia griega. Escribió en defensa de la ortodoxia en contra de herejías posteriores al concilio de Nicea. F. Williams, The Panarion of Epiphanius of Salamis, Book I (Sects 1-46), Book II and III (Sects 47-80), (E.J. Brill, 1987, Leiden, 1993) 79.

14 F. Williams, The Panarion of Epiphanius of Salamis, 620-629.

15 S. Shommaker, The Cult of the Virgin in the Fourth Century: A fresh look at the old and the new Sources. Origins of the cult of the Virgin Mary. Maunder, Chris (dir.), (Bloomsbury, Michigan, 2008) 71-87. 
mahometana ${ }^{16}$. Es relevante precisar que esta controversia se llevó a cabo principalmente en idioma urdu, persa e inglés y no en árabe. Sin embargo, gracias al desarrollo de la imprenta y el periodismo en el Medio Oriente a finales del siglo XIX, este tipo de discusiones llegaron y permearon todo el mundo árabe e islámico. El debate no se limitó solo a defender o atacar a la persona y la misión del Profeta Muhammad como se hizo en el pasado. Esta clase de polémicas además de ser una señal del antagonismo histórico entre el cristianismo y el Islam, también fue una nueva forma de la apologética en ese siglo. Los occidentales, así como los musulmanes estaban discutiendo asuntos relacionados con el cristianismo y el Islam respectivamente con las mismas herramientas lingüísticas; tenían acceso y uso de las mismas fuentes primarias musulmanas, así como también sobre la crítica literaria e histórica de los textos bíblicos. Los temas tratados fueron utilizados para probar por ambos lados la supremacía y verdad absoluta de cada religión ${ }^{17}$.

El principal exponente orientalista de esta controversia, a la que alude Tafsìr al-Manā ${ }^{18}$ fue Karl Gottlieb Pfander ${ }^{19}$, fue un misionero protestante cristiano en la India; Pfander escribió algunos artículos, los cuales fueron publicados por primera vez en diferentes volúmenes de la revista Calcutta Review que dieron origen a esta controversia mahometana. Pfander innovó utilizando fuentes musulmanas no realizado hasta entonces por misioneros en su interpretación del Islam. Pfander escribió tres libros: Miftāh al-Asrar: La llave de los Misterios ${ }^{20}$, Tarīq alHayāt: El Camino de la vida, y al-MizanHaqq: La Balanza de la Verdad. El último fue el que tuvo la mayor influencia y el punto de partida de la controversia. En ese trabajo Pfander considera a Muhammad como un profeta carente de cualidades proféticas y lo llamó El Profeta de la espada en mano o el profeta de la espada. Pfander se aventuró a decir que los

16 W. MuIR, The Mohammedan Controversy, Biographies of Mohammed, Sprenger on Tradition, The Indian Liturgy and the Psalter (T. \& T. Clark, Edinburgh, 1897).vii, $1-63$.

17 W. Muir, The Mohammedan Controversy, 65-88.

18 TM 9: 231ff; TM 9: 286.

19 (1803-1865), Pfander fue un misionero alemán, nacido en Wurttemberg, trabajó para la Basel Mision y la Church Missionary Society; hablaba bien el árabe, urdu y turco. A. A. Powell, "Maulānā RaÊmat AllāhKarānawī and Muslim Christian Controversy in India in the Mid-19 ${ }^{\text {th }}$ Century", en Journal of the Royal Asiatic Society (1976) 44-46, 49.

20 TM 9: 286-287. 
musulmanes no tienen un código moral ${ }^{21}$ y que el Islam se extendió a través de la fuerza en Arabia y en las tierras vecinas ${ }^{22}$. Sir William Muir ${ }^{23}$ fue otro orientalista que compartían los mismos puntos de vista de Pfander. Entre sus escritos, Muir edita un libro en el que presentó no solo las posiciones de Karl Gottlieb Pfander como también la contraparte musulmana de la controversia ${ }^{24}$. En este libro William Muir resume las declaraciones de Pfander en su refutación del Islam y las marcas que se esperan de un profeta de acuerdo con la perspectiva cristiana ${ }^{25}$.

Entre los principales adversarios de Pfander en este debate sobresale la figura de RaḥmatAllāh b. Ḥalīl al-'Uțmānī al-Kairānawī al-Hindi ${ }^{26}$, quien escribió un libro en idioma urdu en 1854 titulado Izhar al-Haqq: la Manifestación de la Verdad. En este RaḥmatAllāh examina varios temas contra el cristianismo, especialmente la Trinidad, la divinidad de Jesús y la corrupción de la Biblia ${ }^{27}$. RaḥmatAllāh quería demostrar la debilidad lógica del tipo de razonamiento a través de la analogía. Un método usado por muchos misioneros en los bazares de la India. Si los cristianos aceptan una verdadera distinción entre las tres personas de la Trinidad, estos están creyendo en una conjunción de contrarios, y son inconsistentes lógicamente, porque aunque ellos aceptan la conjunción de unidad y de la Trinidad real en la deidad, estos sin embargo consideran que es imposible considerar cualquier otra conjunción de unidad y pluralidad. Raḥmat consideraba el Símbolo Atanasiano ${ }^{28}$ el pronunciamiento definitivo cristiano sobre la creencia en la Trinidad. Explicaba la inconsis-

21 K. G. Pfander, The Mizan al-Haqq: Balance of Truth (The religious Tract Society, London, 1910) 326-248.

22 K. G. Pfander, The Mizan al-Haqq: Balance of Truth, 349-367.

23 Un orientalista escocés (1819-1905 CE). Muir se especializó en estudios de la era del profeta Muhammad y los primeros califas. Este trabajo en diferentes puestos en Asia como oficial británico.

24 Muir, The Mohammedan Controversy, 33 ss.

25 Muir, The Mohammedan Controversy, 21-22.

26 RaḥmatAllāh nació en Kairāna, India en 1818. Escribió muchos libros en árabe, persa y urdu. Conocido especialmente por su Izhar al-Haqq; Powell, "Maulānā RaÊmat AllāhKairānawī and Muslim Christian Controversy in India in the Mid$19^{\text {th }}$ Century", 42, 46, 58-63; Muir, The Mohammedan Controversy, 33-34.

27 Citado por Avril Ann Powell as published in two Volumes in Istanbul, 1284 H/1867 M; A. A. Powell, Muslims \& Missionaries in Pre-Mutiny India (Curzon Press, Richmond, 1993) 223.

28 A. Berthold, Patrología, E. Cuevas - U. Domínguez-Del Val (trads.), (EspasaCalpe, Madrid, 1956) 244 ss. 
tencia de la analogía para demostrar este credo. El uso del triángulo: su argumento en contra, a pesar de que los tres ángulos del triángulo son iguales, esto no constituye su esencia en sí mismo y por lo tanto no demuestra la posibilidad de la existencia de tres en uno y uno en tres. Sin embargo, Karl Pfander no utilizó analogías en su defensa de la Trinidad, este la expresó como una verdad revelada (certeza evangélica) y no explicada por la razón ${ }^{29}$. Por el contrario, RaḥmatAllāh manifestaba la importancia de la razón en estos debates ${ }^{30}$.

Los autores de Tafsìr al-Manār tuvieron conocimiento de esta controversia y de las figuras que intervinieron en la discusión. Rashīd Rị̣ā desarrolla un largo ensayo en el volumen siete del comentario después de las explicaciones de los versos Q. 7: 155-15731 sobre las buenas nuevas de la Torá, el Evangelio y sus diferencias. En este Riḍā menciona al-Kairānawī y su obra Izhar al-Haqq ${ }^{32}$. Se hace uso de ese trabajo para expandir diferentes cuestiones en relación con las escrituras cristianas y hace referencias repetidas a al-Kairānawī y a su trabajo ${ }^{33}$. En realidad, al-Kairānawī escribió en urdu y más tarde en árabe. Este salió de la India después de la rebelión india de 1857 y murió en La Meca, teniendo así más oportunidades para influir con sus ideas en el mundo árabe ${ }^{34}$.

La profesora Avril Ann Powell afirma que los primeros oponentes iniciales de Pfander trataron establecer reglas que gobernaran la posibilidad lógica de demostrar lo irracional de la doctrina trinitaria ${ }^{35}$. Estos argumentos fueron retomados por Rạ̣matAllāh en su panfleto sobre la Trinidad Ibțāl al-Tașlīṣ: La Refutación de la Trinidad el cual fue integrado luego como la cuarta parte de su obra Izhar al-Haqq ${ }^{36}$.

29 Powell, Maulānā Râ̂Emat AllāhKairānawū, 51.

30 Powell, Maulānā Râ̂Emat AllāhKairānawī, 52.

31 TM 9: 214-230.

32 TM 9: 231.

33 TM 9: 231, 141, 278, 279, 286, 291, 293, 296.

34 R. A. al-Kairānwī, Izhār al-ḥaqq, Ğuz'ān 1-2 (al-Maṭba'a al-'Amira, al-Qāhira, 1280 H/1867 M). Existe también una traducción en francés de 1880. Muhammad 'Abduh estuvo en París durante su exilio en 1884.

35 Powell, "Maulānā RaÊmat AllāhKairānawī and Muslim Christian Controversy in India in the Mid-19 $9^{\text {th }}$ Century", 49.

36 al-Kairānawī, Iz̧hār al-ḥaqq, 681-772. 
POSICIÓN DE TAFSİR AL-MANÄR

El editor y segundo autor principal de Tafsìr al-Manār: Rashīd Rị̣ā presenta dos ensayos entre las distintas referencias al concepto de Trinidad cristiana en todo su comentario coránico. El primero de estos se encuentra en el volumen seis titulado Fașlfíaqida al-tat lit: Ensayo sobre la creencia trinitaria ${ }^{37}$. Posteriormente, Rị̣ā aborda este tema nuevamente en un segundo ensayo en el volumen décimo del comentario coránico titulado en francés, inglés y árabe: Trinité, Trinity, $\underline{T} u l \bar{u} \underline{t}^{38}$. En este ensayo de catorce páginas, Rị̣ā realiza su mejor exposición y posición personal al respecto. En el primero, Rashīd Riḍā desarrolla una presentación muy elaborada con fuentes occidentales sobre las bases paganas de la Trinidad, especialmente de los pueblos de Oriente y europeos. Rị̣ā Manifiesta lectura, posee las fuentes traducidas al árabe, cita nombres de autores, libros y páginas de estos últimos.

El primer ensayo se encuentra en el volumen sexto del comentario coránico. Rashīd Riḍā comenta los versículos de la sura al-Nisä: Las Mujeres, Corán 4: 171-17339; luego lo complementa con este ensayo sobre la creencia en la trinidad y sus orígenes en pueblos paganos ${ }^{40}$. El comentario sobre estos versículos en relación a la creencia cristiana en la Trinidad manifiesta el rechazo; es una negación, y presentado sobre todo como un mandato divino de la revelación coránica: no digas!/no digan! (Corán 4: 171). Posteriormente, Riḍa hace la presentación de varios autores occidentales y sus textos sobre el origen pagano de esta creencia, así pretende reafirmar varios elementos centrales al Islam. En una primera instancia la unicidad divina, luego la imposibilidad divina de engendrar o de ser engendrado, y la imposibilidad de dividirse en partes o personas y de ser al mismo tiempo verdaderamente trinitario y verdaderamente $u_{n o}{ }^{41}$.

Especialmente, Riḍa sigue en forma textual el libro Bible Myths and their Parallels in Other Religions de Thomas William Doan ${ }^{42}$, el cual menciona diferentes libros y sus páginas, los cuales Rashīd Riḍā repro-

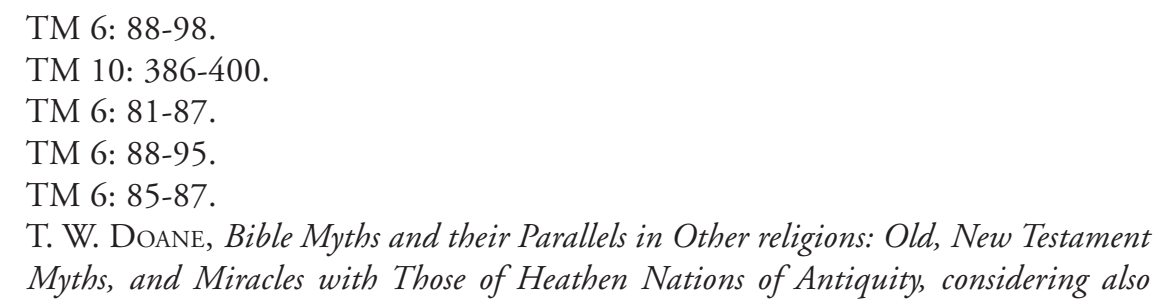
Myths, and Miracles with Those of Heathen Nations of Antiquity, considering also 
duce $^{43}$. Cabe recordar que Rashīd Rị̣ā (1865-1835) era libanés y posiblemente tuvo acceso y conocimiento sobre The Syrian Protestan College fundado en 1863 y denominado después en 1920 como la hoy conocida The American University of Beyrut. Además Beirut fue un centro donde floreció la imprenta y la prensa en el siglo XIX, primeramente en círculos cristianos; de igual manera floreció en Egipto esta actividad literaria y producción literaria, de la cual la revista al-Manār, su casa editorial y el comentario coránico en cuestión son fruto de estos desarrollos ${ }^{44}$.

Rashīd Riḍa afirma con este autor: Thomas Doane que la creencia en la Trinidad fue introducida por las poblaciones paganas cristianizadas. Varios autores son mencionados para reafirmar la creencia. En cuanto a esto, la Trinidad está presente en religiones como el hinduismo, budismo y religiones chinas. El primero de los autores mencionados es Thomas Maurice ${ }^{45}$, quien escribió la obra titulada Indian antiquities ${ }^{46}$ y reafirma la posición de Riḍa sobre el origen politeísta hindú de la creencia en la Trinidad. Otro autor es George Faber ${ }^{47}$ con su libro The Origin of pagan Idolatry ${ }^{48}$, quien confirma la idea de Thomas Doane ${ }^{49}$. Riḍa también menciona otro autor llamado James Bonwik con su libro Egyptian Belief and Modern Thought ${ }^{50}$. Bonwik afirma que los egipcios antiguos creían que la palabra: al-kilma fue utilizada por Dios para crear; asimismo Platón y Aristóteles conocían esta creencia ${ }^{51}$. Otro autor es Godfrey Higgins $^{52}$ el cual manifiesta que estos pueblos y los persas hablan de la palabra creadora y de Marduk; en los pueblos caldeos, asirios y fenicios

Their Origin and Meaning (The Commonwealth Company, New York, 1882) 304-315.

43 TM 6: 90.

44 A. Ayalon, The Press in the Arab Middle East: A History, In Cooperation with The Moshe Dayan Center For Middle Eastern and African Studies (Oxford University Press, New York-Oxford, 1995) 13-44.

45 (1754-1824), este fue un historiador y orientalista británico.

46 T. Maurice, Indian Antiquities, 7 vols (University of London, London, 1806).

47 George Stanley Faber (1773-1854) fue un teólogo y clérigo anglicano.

48 G. S. FABER, The Origin of Pagan Idolatry ascertained from Historical Testimony and Circumstantial Evidence, 3 vols (For F. and C. Rivingtons, London, 1816).

49 TM 6:89.

50 J. Bonwik, Egyptian Belief and Modern Thought (C. Kegan Paul, London, 1878).

51 TM 6: 90.

52 TM 6: 91; G. Higgins, Anacalypsis: An Attempt to Draw Aside the Veil of the Saitic Isis; or an Inquiry into the Origin of Languages, Nations and Religions, Volumes 1-4 (Longman, Rees, Orme, Brown, Green and Longman, London, 1836). 
se habla del hijo de Dios ${ }^{53}$. Igualmente, Riḍā menciona a James Coles Pritchard ${ }^{54}$, quien escribió el libro Analysis of egyptian mythology. Este sostiene que no hay duda del origen oriental de la creencia en el hijo primogénito de una trinidad. La cual es el origen de la creencia pagana griega, romana y europea actual ${ }^{55}$.

El editor de Tafsìr al-Manār no se conforma en presentar y comentar estas evidencias de autores occidentales para justificar el origen pagano de la creencia de la Trinidad, sino que luego aborda las escrituras bíblicas, Antiguo y Nuevo Testamento como también el desarrollo teológico de la Trinidad en el segundo ensayo del décimo volumen ${ }^{56}$. Por una parte, Rị̣ā utiliza fuentes cristianas, en este caso la Biblia: Antiguo y Nuevo Testamento; por otro lado cita textualmente y reproduce un comentario bíblico traducido al árabe y presente en Beirut en la facultad arriba mencionada que se convertirá en la Universidad América de Beirut. Además Rị̣ā demuestra su conocimiento del desarrollo teológico sobre la Trinidad desde la época Antigua hasta la Moderna. Esto se confirma en su conocimiento de herejías, concilios, y posturas teológicas al respecto.

En primer lugar, Rashīd Riḍa define la Trinidad como un término que designa en el cristianismo la presencia de tres personas juntas en la divinidad: el Padre, el Hijo y el Espíritu Santo. Este añade que es la enseñanza de las iglesias: católica, oriental y el grupo de iglesias protestantes excepto por algunas. Quienes se adhieren a esta enseñanza creen que concuerda con los textos de la Biblia. La doctrina explora la forma de la generación de la segunda persona, la emanación de la tercera persona, y además sobre lo que une a las tres y las distingue. Rashīd Riḍā es consciente que el término no se encuentra en la Biblia. En el Antiguo Testamento no existe ningún versículo que hable abiertamente de ello. Los teólogos han articulado un gran número de versículos para indicar la imagen completa de la doctrina. Riḍa argumenta en contra de la creencia que si se consultan diferentes comentarios bíblicos no se hallarán dos significados claros, inequívocos y convincentes ${ }^{57}$.

TM 6: 91.

54 (1786-1848) Médico y etnólogo británico.

55 TM 6: 91-92.

56 TM 10: 386-400.

57 TM 10: 386. 
En segundo lugar, Rị̣ā demuestra su conocimiento del desarrollo y discusión de la doctrina trinitaria en la historia del cristianismo. Riḍā cita a Teófilo de Antioquía (m. 183 d.C.) como el primero que utiliza un vocablo para referirse a la creencia: trías, luego menciona a Tertuliano (ca. 160-220 d.C.), quien acuña la palabra trinitas en latín, sinónimo del término actual en otras lenguas occidentales: trinidad. Consiguientemente, varias herejías previas al concilio de Nicea son mencionadas: ebionitas ${ }^{58}$, seguidores de Sabelio ${ }^{59}$ y modalistas ${ }^{60}$, Arrio $^{61}$ y macedonios ${ }^{62}$.

Para continuar, Rashīd Riḍā explica y da fechas de cómo los concilios de Nicea (325), Constantinopla I (381) y el concilio de Córdoba (589) formulan y dan una versión oficial de la creencia en la Trinidad: el Hijo y el Espíritu Santo son iguales al Padre en la unidad de la divinidad. Además, el Hijo fue concebido desde la eternidad del Padre. Y el Espíritu Santo emana del Padre. Luego el concilio de Córdoba afirmó que el Espíritu Santo emana también del Hijo. Esta versión fue aceptada especialmente por la iglesia de Occidente, es decir la romana o Católica, mientras que la Oriental al principio se adhirió a esta formulación pero se separó del elemento referente a la emanación del Espíritu Santo ${ }^{63}$. En cuanto a las iglesias nacidas de la Reforma Protestante, estas se adhieren a la versión tradicional oficial.

Rashīd Rị̣ā pasa entonces a realizar su apologética a través del comentario tanto de los textos coránicos, los cuales él recuerda ya han sido tratados antes en el comentario coránico como también de textos bíblicos. Para esto utiliza además una exégesis bíblica editada y traducida por un médico y botánico norteamericano que vivió y trabajó en Beirut: George Edward Post ${ }^{64}$. Es importante observar como Rashīd Riḍā

58 Secta judeocristiana de los orígenes del cristianismo. Rashīd Riḍā afirma que estos sostenían que el mesías era un hombre solamente. TM 10: 387.

59 (ca. 215 d. C.), Sabelio fue un sacerdote y teólogo romano.

60 Los modalistas según Rashīd Riḍā describen al Padre al hijo y al espíritu santo como imágenes o modos distintos de la divinidad que se manifiesta a la humanidad en la historia. TM 10: 387.

61 Arrio (256-336 d.C.), sacerdote egipcio en Alejandría. Rashīd Riḍā identifica a los arrianos como aquellos que sostenían que el hijo o la segunda persona no era eterno como el padre, creado por el padre y por ende subordinado al él. TM 10: 387.

62 Estos negaban que el espíritu santo fuese una persona de la trinidad. TM 10: 387.

63 TM 10: 387.

64 (1838-1909), viajó a Beirut como misionero presbiterano y trabajó como profesor de cirugía en el Syrian Protestant College of Beirut; G. PosT, Qāmūs al-Kitāb al- 
explica el significado coránico y aun bíblico del título: "el mesías hijo de Dios" en el comentario del verso: "Los judíos y los cristianos dicen: "Somos los hijos de Allah y Sus predilectos»". (Corán 5: 18) ${ }^{65}$. Este término, según Rị̣ā, se aplica primeramente a Adán (Lc 3: 38), Jacob (Ex 4: 22), Israel y Efraím (Jr 9: 31), también se aplica a los ángeles y fieles piadosos como los diferencia el mesías de los hijos del diablo (Jn 8: 4144), y Salomón ${ }^{66}$. Para Rashīd Riḍā el uso de este término que no es más que figurativo en el lenguaje coránico y bíblico; ha sido utilizado por los cristianos en forma literal únicamente para el Mesías y figurativo para el resto de personajes ya citados ${ }^{67}$. Para acentuar, Riḍa recuerda que esta creencia de la Trinidad ha sido introducida en la religión de los profetas (judaísmo), proveniente de creencias de pueblos paganos como anteriormente se explicó ${ }^{68}$.

Es así como Rashīd Riḍā toma el comentario bíblico de George Edward Post con citas textuales para continuar con su refutación de los títulos atribuidos al mesías y por ende la refutación de la creencia en la Trinidad. El primer término a comentar es el nombre de Allāh: Dios. Post describe los atributos de Dios como creador, omnisciente, ilimitado en sus facultades, es espíritu y se revela a la humanidad. Es en Jesucristo, su hijo que se revela completamente ${ }^{69}$. El segundo término aborda la naturaleza de Dios. La expresión de tres personas iguales en esencia (Mt 28: 2, 19; 2 Cor 13: 14); Dios el padre, Dios el Hijo y Dios el Espíritu Santo. Al padre le corresponde la creación (Salmos 33: 6; Cor 1: 16; Hb 201). Al Hijo le corresponde la redención y al Espíritu Santo la purificación. No son tres personas dividiéndose todas las obras divinas, sino más bien realizándolas juntos, por igual ${ }^{70}$. La Unidad de Dios es el siguiente término. Post indica que la unicidad divina es reafirmada en más en el Antiguo Testamento que en el Nuevo. En el Antiguo Testamento hubo un llamado a separarse de la idolatría y cultos paganos (Dt 6: 4). El último título o término tomado del comentario es el de hijo de

Muqaddas: Arabic Bible Dictionary, Muğallad 1 (al-Maṭba'a al-Amerīkāniyya, Bayrūt, 1894) 134-135.

65 TM 6: 306-320.

66 TM 10: 88-89.

67 TM 6: 81, 95, 314.

68 TM 10: 390.

69 Ibid

70 Ibid. 
Dios atribuido a personas como Adán (Lc 3: 38), a los fieles y guiados por el espíritu de Dios (Rm 8: 14; 2 Cor 6: 18). Este título se aplica al Mesías como Hijo único y eterno de Dios (Juan 1: 18, 5: 19-26; 9: 35, 38; Mateo 11:27, 16: 16; 21:37), quien enseña a llamar a Dios: Padre, no por filiación directa sino por adopción ${ }^{71}$.

Después de esta citación del comentario bíblico de George Post, Rashīd Riḍā explica que estos elementos demuestran la ambigüedad y debilidad en sí de los planteamientos y de la creencia en la Trinidad. En primera instancia, Rashīd Rị̣a explica que este concepto de la Trinidad no fue conocido ni manejado por los profetas del Antiguo Testamento, por consiguiente esta doctrina es una innovación o herejía aparecida con el cristianismo ${ }^{72}$. En segunda instancia, el texto: "Y bautícenlos en el nombre del padre y del hijo y del espíritu santo" (Mt 28: 19), no indica que las personas de la Trinidad tengan una misma naturaleza ni que diferencie las actividades de cada uno, como tampoco lo indica la cita: "La gracia del Señor Jesucristo, el amor de Dios, y la comunión del Espíritu Santo sean con todos vosotros. Amén”. (2 Cor 13: 14). Riḍā explica que Pablo fue el iniciador de las doctrinas actuales del cristianismo, lo cual no recibió ni del mesías ni de los demás apóstoles. En relación al versículo: "Por la palabra del Señor fueron hechos los cielos, Y todo el ejército de ellos por el aliento de su boca". (Salmo 33: 6), el término kilma: palabra que se alude al Mesías, no fue conocido por David con la connotación que tiene en los escritos de Juan (Jn 1: 1-5; 1 Jn 1: 1).

El argumento que más señala y reitera Rashīd Riḍā en contra de la creencia es que no hay ninguna señal ni alusión literal sobre ello en el Antiguo Testamento. En comentarios judíos sobre el libro del Génesis, no existe esta interpretación. Como tampoco la alusión a la naturaleza trinitaria de Dios, la cual no permite una interpretación alegórica u ta’wīl: interpretación (esotérica) ${ }^{73}$. Esto según Rashīd Riḍā es el resultado de integrar elementos paganos en el cristianismo. Es así como se cita a Daniel 3: 91-92 donde el rey Nabucodonosor utiliza el titulo hijo de Dios. Para Rị̣ā, los cristianos niegan ser paganos o idolatras y asimismo utilizan términos de pueblos paganos ${ }^{74}$.

\footnotetext{
1 TM 10: 391.

72 TM 10: 391-392.

73 TM 10: 393; Rippin, "Tafsir", 8950.

74 TM 10: 394.
} 
Hay otro aspecto a resaltar, el comentario niega tanto la paternidad literal de Dios como la adopción. En primer lugar, se destaca la omnipotencia divina y su unicidad, cualquier asociación o mención de hijos con la divinidad se atribuye a politeísmo. Para Rị̣ā, Dios es más grande que eso. Por otro lado, la adopción en Islam es rechazada para atribuírsele a Dios y también a los seres humanos. En el Islam no está permitida la adopción legal ${ }^{75}$. Rashīd Rị̣ā vuelve a reafirmar que el título hijo de Dios no demuestra una realidad sino más bien un sentido metafórico. La Trinidad por consiguiente agrede la divinidad por aplicarle antropomorfismo. Esto va en contra de la trascendencia divina. El término hijo de Dios o hijos de Dios se aplica solo a los creyentes en sentido de filiación espiritual para quienes son fieles a él. Así para Riḍā, la doctrina contradice la creencia en la unicidad divina manifestada por los profetas y se opone a la razón ${ }^{76}$. Rashīd Rị̣ā manifiesta cómo los cristianos destruyeron los verdaderos escritos del evangelio del Mesías. Esta última es una alusión a su reiterada corrupción de las escrituras ${ }^{77}$.

Para Rashīd Rị̣ā, como para algunos musulmanes de su tiempo, y aun contemporáneos, el verdadero evangelio olvidado y rechazado por los cristianos es el evangelio pseudoepígrafo ${ }^{78}$ de Barnabas $^{79}$. En la aplicación método histórico-crítico a este evangelio se demuestra que fue

75 Corán 33: 4-5, 37; un motivo es no permitir que los huérfanos sean despojados de sus propiedades por parte de los padres adoptivos; en segundo lugar, la adopción no permitiría a un hombre casarse con la ex esposa de su hijo adoptivo.

76 Christine Schirmacher explica que en la perspectiva islámica la trinidad se cataloga como idolatría, por asociar otros seres a la unicidad de Dios; al reducir al eterno y todopoderoso y trascendente al estado de la creación, lo cual es impensable; y sobre todo que esta creencia va en contra de la razón humana. C. SCHIRRMACHER, The Islamic View of Major Christian Teachings, WEA: World Evangelical Alliance, IIRF: International Institute for Religious Freedom, The WEA Global Issues Series 99, Volume 2 (Verlagfür Kultur Wissenschaft, Bonn, 2008) 9.

77 TM 5: 140-141; TM 10: 398.

78 En estudios bíblicos y literarios estos escritos son falsamente atribuidos a un autor. Y rechazados como canónicos, la mayor parte de estos escritos fueron realizados en la era cristiana. Por ejemplo La odas de Salomon. J. H. Charlesworth, "Biblical Literature: Apocrypha and Pseudoepigrapha" en Encyclopedia of Religion, Second Edition, Volume 2, L. Jones (dir.), (Macmillian Reference USA-Thomson \& Gale, Farmington, Hills (MI), 2005) 901-904.

79 L. RAGG - L- RAGG (dirs.), The Gospel of Barnabas, Edited and translated from the Italian Manuscripts in the Imperial Library at Vienna (Islamic European Cultural Centre, Roma, 1986). 
atribuido falsamente a un tal apóstol Barnabas. El origen posiblemente fue en un ambiente español de la Edad Media. Su autor es posiblemente un musulmán convertido a la fuerza durante la reconquista de España y emigrado hacia otro lugar en Europa. El evangelio concuerda con la doctrina islámica del mesías y de los orígenes del Islam. Este alude a la venida de otro profeta: Muhammad. Y Rashīd Riḍā lo utiliza en su comentario para defender la personalidad del profeta del Islam ${ }^{80}$. Para Rashīd Riḍā, las palabras del mesías en los actuales evangelios no son las verdaderas como tampoco sus hechos, y una prueba es la cita de Juan 21: $25^{81}$.

Para resumir, la explicación que Tafsìr al-Manār hace de la creencia en la Trinidad manifiesta la visión o concepción clásica islámica. Para el Islam, la unicidad divina se rompe y es agredida por esta creencia en cuanto que, primero asociaría otras personas a la divinidad dando el parecer de un politeísmo encubierto. De otro lado, la persona de Jesús, el Mesías, introduce una persona física en la divinidad trascendente y espiritual. Otro elemento en contra de la creencia es que esta implica un antropomorfismo que es negado rotundamente por el Islam, solo en sentido figurado. Por otra parte, las nociones y términos utilizado de la filosofía griega crean una complicación para entender por parte de los musulmanes la experiencia que vivieron los primeros cristianos. Experiencias que fueron plasmadas en los escritos evangélicos y difíciles de plasmar y explicar totalmente en lenguaje filosófico o teológico. Sin embargo, la revelación coránica es la base para refutar tal doctrina dado que es el fundamento de la fe islámica ${ }^{82}$.

ACTUALIDAD: IMPORTANCIA DE LA DISCUSIÓN Y NUEVAS PERSPECTIVAS DE DIÁLOGO

La posición apologética de Tafsīr al-Manār obedece a diversos aspectos que fueron articulándose e influenciando una relación de competencia y rivalidad entre las dos religiones monoteístas. Por un lado, la historia y las consecuencias de las cruzadas de los siglos XII al XIII, que dejaron una huella dolorosa en el mundo Islámico del momento y una visión del Occidente como un rival tanto religioso como político.

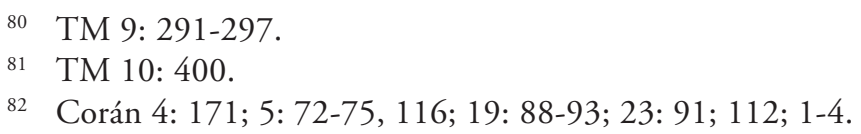


Para muchos la ocupación de Tierra Santa y otros territorios del Medio Oriente no fueron vistos como consecuencia de una motivación religiosa sino expansionista y colonialista de los llamados Ifrang: franceses, término asociados a los cristianos de Occidente ${ }^{83}$. De otra parte, el nuevo colonialismo europeo: francés e inglés de los siglos XVIII y XIX acrecentaron esta visión expansionista del Occidente. En el mundo Islámico esto fue visto como un castigo divino por no adherirse a los preceptos del Corán. De los siglos XIV a XVII el Islam había conocido otro momento de gloria y expansión bajo el imperio Otomán, rival del Occidente y el más potente y feroz a todo nivel: naval, bélico y comercial.

El siglo XX ha testimoniado un viraje en la actitud de apertura, diálogo, mutuo conocimiento y posibles formas de relación entre ambas religiones. Varios aspectos han motivado este camino que aún se construye en medio de otras vertientes fundamentalistas: a) La independencia de los países del Medio Oriente, África y Asia con mayoría de población musulmana. b) La creación de las Naciones Unidas y otras organizaciones afines que promueven la cooperación, la paz y el progreso de las naciones. c) La nueva perspectiva del multiculturalismo y de su puesta en práctica: de respeto, tolerancia, coexistencia y autonomía de las culturas y pueblos. d) Las migraciones y formación de sociedades multiculturales en Europa, Norteamérica y otros lugares del mundo. e) La apertura e iniciativa de diálogo interreligioso iniciado por la Iglesia Católica con el Vaticano II y sus documentos inspiradores como Nostra Aetate. Esta iniciativa ha inspirado además el desarrollo de la teología del diálogo interreligioso como también los empeños prácticos hacia ella. Esto último podría ser resumido a través de los aportes del teólogo suizo Hans Küng, quien hace tres afirmaciones importantes sobre el futuro del diálogo interreligioso entre las tres religiones monoteístas al final de su estudio y publicación sobre las mismas. En un primer lugar, las tres religiones tienen un potencial efectivo para el futuro basadas en su riqueza espiritual y ética; en segundo lugar, todas ellas pueden compartir a través del mutuo entendimiento y la colaboración; y finalmente, un mundo en paz y más justo será el resultado de la contribución indispensable de todas ellas ${ }^{84}$.

83 A. Maalouf, Las Cruzadas vistas por los árabes, M. T. Gallego - M. I. Reverte (trads.), (Alianza Editorial, Madrid, 1989).

84 H. KüNG, Islam, Past, Present and Future, J. Bowden (trad.), (Oneworld, Oxford, 2007) 661. 
Por otro lado, se aprecia el surgimiento de personalidades intelectuales del mundo islámico abiertas a los tiempos modernos, al diálogo y a la crítica mutua constructiva. Entre algunos intelectuales destacados musulmanes sobresalen un número de personalidades, tres ya fallecidos: Fazlur Rahman, Mohamed Arkoun y Nasr Abu Zayd. Otros que aún continúan produciendo y articulando un discurso diferente al de los autores de Tafsīr al-Manār como por ejemplo Mahmoud Ayoub y Mohamed Talbi. Fazlur Rahman y la mayor parte de los teólogos, filósofos, jurisconsultos y eruditos musulmanes del siglo XX fueron influenciados por la perspectiva iniciada por Tafsìr al-Manār en relación a la necesidad de reforma del Islam, el esfuerzo por adaptar el Islam y su tradición a los tiempos modernos y problemas contemporáneos ${ }^{85}$. Su vida y trabajo estuvo marcado por un diálogo con el Occidente siempre enraizado y convencido con su tradición islámica.

El reconocido intelectual franco-argelino Mohamed Arkoun, fallecido en 2010, fue más allá que los autores de Tafsìr al-Manār en temas relacionados con el diálogo islamo-cristiano. Este no permaneció en el campo de la apologética. Arkoun llamaba a un análisis y evaluación histórica de cada tradición religiosa y de su propio patrimonio. Por otro lado, en relación a las iniciativas mundiales como la Conferencia Mundial de las Relifiones por la Paz de 1097 en Lovaina-Bélgica, este argumentaba primeramente, que las religiones tienen necesidad de conversión mutua y respeto por las posiciones religiosas del otro. Aparte de defenderlas, las religiones deben buscar de aplicar estas visiones religiosas a resolver y satisfacer los problemas y aspiraciones de los seres humanos a escala global $^{86}$. Cabe destacar que Mohamed Arkoun reconoce que el antagonismo histórico visto desde la iniciativa actual de la Iglesia Católica es una cuestión del pasado ${ }^{87}$.

Para el profesor Sabri Yilmaz ${ }^{88}$, la unicidad de Dios es un principio base e indispensable, por lo tanto es imposible erradicarlo. De la misma

F. Rahman, Islam and Modernity: Transformation of an Intellectual Tradition (Chicago University Press, Chicago, 1982).

86 M. Arkoun, "Propositions Pour Une Pensée Religieuse" (En Vue de la Conference Mondiale des Religions pour la Paix) en Islamo christiana 41 (1978) 197-206.

87 M. Arkoun "Is Islam Threatened by Christianity?" en Islam: A Challenge for Christianity, H. Küng - J. Moltmann (dirs.), (Orbis, Maryknoll, 1994) 49-57.

88 Este es profesor en Akdeniz Üniversitesi İlahiyat Fakültesi, Kelam Anabilim Dali Ögretim Üyesi, Türkiye. 
manera la creencia en la trinidad es un principio fundamental para el cristianismo. Por consiguiente, la religión es una cuestión de fe y no de la razón y cada creyente de cada religión tiene el derecho de defender su creencia. Sin embargo, en el ambiente del diálogo interreligioso actual, no se trata de defender la veracidad de su propia creencia y al mismo tiempo de atacar la creencia del otro. Según el principio coránico: "Vosotros tenéis vuestra religión y yo la mía” (Corán 109: 6), se presupone que cada creyente, de cada religión, puede vivir pacíficamente en mutuo respeto y reconocimiento del otro. El diálogo teológico no puede impedir la cooperación y la promoción de la paz mundial ${ }^{89}$.

En la perspectiva de Mahmud Ayoub, un teólogo y erudito musulmán libanés, comprometido con el diálogo entre Islam y Cristianismo, el diálogo debe incluir varios aspectos entre los cuales están lo intelectual, lo espiritual y lo práctico o de vida. La discusión doctrinal debe servir para conocer al otro principalmente y disipar malentendidos del pasado. Pero lo más importante debería ser centrarse en los valores comunes de ambas religiones. Ambas religiones podrían centrarse en la comunión de fe, tanto cristianos como musulmanes son creyentes en el único Dios, y esta comunión de fe y de vínculo con Dios es la base principal de todo diálogo. Por otra parte, el Corán invita a un diálogo en el respeto y en la comunión de fe:

No discutáis sino con buenos modales con la gente de la Escritura, excepto con los que hayan obrado impíamente. Y decid: «Creemos en lo que se nos ha revelado a nosotros y en lo que se os ha revelado a vosotros. Nuestro Dios y vuestro Dios es Uno. Y nos sometemos a Él». (Corán 29: 46) ${ }^{90}$.

Otro exponente de este cambio es el historiador y erudito tunecino Mohamed Talbi, también empeñado en el diálogo de civilizaciones y religiones. Este muestra que tanto el Islam como el cristianismo, experimentan hoy una descristianización y una desislamización respectivamente. Lo cual es un reto para cada una de ellas. Por una lado, hay confusión en el mundo islámico en identificar qué es el Islam, si una cultura

89 S. Yilmaz, "A Muslim Theologian's Approach to the Doctrine of the Trinity in The Case of Qadfi Abd al-Jabbar", en The Journal of International Social Research, 6/24 (2003) 435.

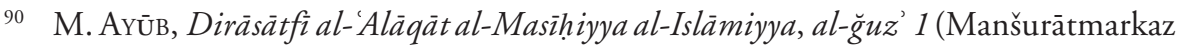
al-dirāsāt al-masî iyya al-islāmiyyafĭğami āt al-Balamand, al-Kura, Lubnān, 2000) 24-25, 206, 208-210. 
y civilización o una religión de fe y espiritualidad. Por esta razón, Talbi plantea que el camino del Islam no puede ser el integrismo o fundamentalismo. El verdadero camino entre el Islam y el Occidente es el del diálogo entre cristianos y musulmanes, entre occidentales y orientales ${ }^{11}$.

\section{CONCLUSIÓN}

Si bien esta nueva tendencia contemporánea hacia el diálogo interreligioso entre las dos religiones monoteístas: el Islam y el Cristianismo es reciente (en todas las esferas: teológico, espiritual, de convivencia y cooperación), puede ser considerada una tarea en plena construcción. Sin embargo, la nueva tendencia es ya un avance en términos de tolerancia, respeto y oportunidad de vivir cada cual afirmando su propia identidad y tradición. Los autores de Tafsīr al-Manār estuvieron ambos enfrentados a un mundo en cambio, a diferentes desafíos que amenazaban su entorno y de acuerdo a este contexto histórico y social respondieron en su empeño de reforma. Ambos mantuvieron posiciones apologéticas en relación al Occidente y al Cristianismo. Y sus posiciones fueron una respuesta proveniente de su profundo convencimiento religioso islámico como también fruto de un pasado cargado de antagonismos entre su religión islámica y la presencia y encuentro con el Cristianismo. En este contexto, es importante anotar el cambio de apologética al diálogo que la mayor parte de teólogos, filósofos, juristas y eruditos musulmanes contemporáneos manifiestan. Primeramente en su relación con el Occidente y no solo con el cristianismo sino también con otras religiones mundiales. No se trata ya en atacar y refutar (por ejemplo la doctrina cristiana trinitaria de la parte de los musulmanes) sino en tratar de entender al otro y hacer juntos de este mundo un lugar más habitable. Ambas religiones tienen un compromiso de responsabilidad social en el mundo y de vivencia de sus valores: la solidaridad, la reconciliación y la esperanza que actualmente no son una prerrogativa única de las religiones.

91 M. TAlBi, "Islam et Occident au-delà des affrontements; des ambigüités et des complexes" en Islamo christiana 7 (1991) 57-77. 
